\title{
Anti-HA Epitope Monoclonal Antibody MEDI8852
}

National Cancer Institute

\section{Source}

National Cancer Institute. Anti-HA Epitope Monoclonal Antibody MEDI8852. NCI

Thesaurus. Code C131295.

\begin{abstract}
A human immunog lobulin (Ig) G1 kappa monoclonal antibody (mAb) targeting a unique epitope in the stalk of the influenza A hemagglutinin ( $\mathrm{HA}$ ) protein, with broad influenza A virus neutralization activity. MEDI8852 was derived from an antibody isolated from human memory B-cells from patients previously infected with influenza caused by type A strains that was further optimized to increase neutralization potential. Upon infusion, MEDI8852 targets and binds to a region within the stalk of the HA protein that is highly conserved amongst all influenza A virus subtypes. This neutralizes and prevents essential steps of the viral lifecycle, thereby blocking infectivity of all influenza A virus subtypes. HA, a glycoprotein found on the surface of the influenza virus, plays a key role in viral attachment and cell entry.
\end{abstract}

